\title{
DISCURSOS, PRÁTICAS ORGANIZATIVAS E PICHAÇÃO EM BELO HORIZONTE
}

\section{GLAUCE CRISTINE FERREIRA SANTOS VIEGAS}

Mestra em Administração pelo Centro de Pós-Graduação e Pesquisa em Administração da Universidade Federal de Minas Gerais (Cepead-UFMG).

Professora do Instituto de Ciências Sociais Aplicadas

do Centro Universitário de Belo Horizonte ((Icsa-UniBH).

Rua Diamantina, 567, $6^{\circ}$ andar, Lagoinha, Belo Horizonte - MG - Brasil - CEP 3171 10-320

E-mail: glauceviegas@hotmail.com

\section{LUIZ ALEX SILVA SARAIVA}

Doutor em Administração pelo Centro de Pós-Graduação e Pesquisa em Administração da Universidade Federal de Minas Gerais (Cepead-UFMG).

Professor adjunto III do Departamento de Ciências Administrativas da Universidade Federal de Minas Gerais (UFMG).

Avenida Antonio Carlos, 6.627, Pampulha, Belo Horizonte - MG - Brasil - CEP $31270-901$

E-mail: saraiva@face.ufmg.br

Este artigo pode ser copiado, distribuído, exibido, transmitido ou adaptado desde que citados, de forma clara e explícita, o nome da revista, a edição, o ano, e as páginas nas quais o artigo foi publicado originalmente, mas sem sugerir que a RAM endosse a reutilização do artigo. Esse termo de licenciamento deve ser explicitado para os casos de reutilização ou distribuição para terceiros. Não é permitido o uso para fins comerciais. 


\section{RESUMO}

A cidade tem sido encarada tradicionalmente na administração sob a ótica funcionalista, ao ser entendida como campo de atuação profissional ou objeto da administração pública e gestão urbana. Todavia, estudos que versam sobre a urbe em uma perspectiva não funcionalista têm se tornado cada vez mais recorrentes, principalmente a partir de uma visão que focaliza a complexidade urbana e evoca a vida social organizada de indivíduos e grupos oprimidos em diversos âmbitos sociais. Neste artigo, buscamos analisar os discursos que orientam práticas organizativas relacionadas à pichação em Belo Horizonte, o que foi feito mediante um estudo qualitativo baseado em análise do discurso. Além de pesquisa em documentos oficiais sobre as ações governamentais no combate à pichação, foram efetuadas entrevistas individuais em profundidade com nove sujeitos, entre gestores públicos municipais responsáveis pelo combate à pichação, indivíduos da sociedade civil participantes das ações do projeto municipal e representantes da pichação belo-horizontina. O tratamento dos dados foi efetuado por meio da análise francesa do discurso, pela qual se buscou a identificação e análise de aspectos e elementos discursivos segundo roteiro constituído por: I. seleções lexicais; 2. percursos semânticos; 3. interdiscursividades; 4. discursos principais; 5 . reflexão e refração linguísticas; 6 . aspectos ideológicos combatidos e defendidos; e 7. posicionamentos discursivos em relação aos discursos hegemônicos na sociedade. Os principais resultados sugerem que o governo da cidade tanto orienta as representações de combate à pichação como é pressionado para enfrentar o fenômeno segundo os vários modos de fazer, pelos quais imperam os instrumentos de controle sobre as práticas de organização da cidade e se instituem agentes sociourbanos de legitimação estratégica. Conclui-se que a gestão pública é ressignificada pelos distintos atores sociais, em particular pelos pichadores, que adotam uma espécie de ética do picho, que antagoniza o programa da prefeitura, à conduta policial e ao pensamento dominante sobre a pichação e os pichadores, manifestando sua posição por meio da pichação. 


\section{PALAVRAS-CHAVE}

Cidade. Práticas organizativas. Discurso. Pichação. Gestão urbana.

\section{CONSIDERAÇÕES INICIAIS}

A cidade tem sido encarada tradicionalmente como objeto de estudo na administração sob a ótica funcionalista, ao ser entendida como campo de atuação profissional ou objeto da administração pública e gestão urbana. Nesses campos de saber, o espaço urbano é reificado, o que norteia o mainstream dos estudos organizacionais sobre a gestão de cidades. Todavia, estudos que versam sobre a urbe em uma perspectiva não funcionalista têm se tornado cada vez mais recorrentes, principalmente a partir de uma visão que focaliza a complexidade urbana e evoca a vida social organizada de indivíduos e grupos oprimidos em diversos âmbitos sociais.

Mas, afinal, o que é a cidade? Talvez haja uma ideia clara de que qualquer habitante saiba o que ela é, posto que a vivencia e, mutuamente, constrói o seu cotidiano (Carlos, 2008). A cidade é mais um mosaico do que algo uniforme, entendida por uma esfera de conhecimento ou um grupo de pessoas (Magnani, 2008). Por isso, propicia uma instabilidade crônica, pela qual são preconizados constantes tentativas de equilíbrio, reajustamentos e relativo controle (Mac-Allister, 200I), os quais implicam interações competitivas entre atores das distintas esferas de poder (Sánchez, 200I).

Se existe um limite para a intervenção no que de fato pode ser a urbe, talvez seja possível afirmar que ele foi desafiado pela dissidência das manifestações populares de junho de 2013 em todo o Brasil. Nesse momento, as questões urbanas relacionadas ao pensamento político insurgiram do imaginário compartilhado pelos inúmeros cidadãos em suas interações e ocupações citadinas, como em uma intervenção coletiva ou um apelo para desvios de trajetos. Se a cidade for entendida justamente como lugar de produção de desvios de direção e de novas manifestações, talvez se possa falar mais em possíveis intercessões sociais. $\mathrm{Na}$ órbita de antigas e novas práticas e integrações tensionadas na questão urbana, eixos políticos e sociais vivificam a cidade, provocando retornos reflexivos ao passado sem, contudo, perder de vista o futuro.

Em Belo Horizonte, o contexto não é diferente, trazendo dilemas que abrangem diferentes dimensões de análise organizacional na gestão pública municipal, como será indicado por meio da análise do programa Movimento Respeito por BH e do Projeto de Combate à Pichação, que trazem novas discussões aos 
estudos organizacionais, como as questões relacionadas à prática da pichação na cidade. De acordo com documentos oficiais divulgados pela Secretaria Municipal de Segurança Urbana e Patrimonial [SMSEG] (20I3), a busca pelo combate a essa forma de manifestação urbana tem sido abordada por ações que se integram estrategicamente e não só sustentam as seguintes dimensões, mas também as orientam:

- Estética: visa à restauração e recuperação do bem público, ao respeito e à preservação do espaço urbano. Essa dimensão é notada nas ações de despiche.

- Cooperativa: ocorre por meio de interfaces para educação infantil, conscientização social e redirecionamento dos jovens infratores a partir dos canais encontrados na arte urbana ou cultura de rua, como o grafite. Essa dimensão é comungada nas ações de sensibilização.

- Legal: relaciona-se à legislação antipichação com foco na segurança pública, reparação do dano, coibição e punição dos infratores. Essa dimensão é observada nas ações de repressão.

Essa lógica de atuação formatada pela gestão municipal pode ser justificada pela complexidade e consentânea dificuldade de lidar com a pichação na cidade. A pichação é um fenômeno difícil de caracterizar, principalmente pelas ocorrências subjetivas e urbanas, bem como por suas nuances que variam global e localmente e nas cidades brasileiras, sendo tratadas por políticas públicas de enfrentamento para erradicação. É, assim, um circuito permeado por muitas noções e adornado por integrações a movimentos contraculturais, como o hip-hop. No sentido exposto, a atuação sociourbana pressupõe interesses conflitantes e significados dispersos. Há uma linha tênue entre os direitos e deveres dos diversos agentes, bem como entre o significado de suas percepções sobre a urbe e suas práticas de organização do espaço público. Buscamos, então, analisar os discursos que orientam práticas organizativas relacionadas à pichação em Belo Horizonte.

Diante desse objetivo, o presente estudo segue com os referenciais teóricos acerca da cidade nas concepções sobre organização e práticas organizativas. Os aspectos metodológicos para consecução do trabalho de natureza qualitativa são descritos antes da análise dos dados, que evidencia os aspectos da cidade estratégica, na qual também constam interesses públicos e leituras sociais divergentes e convergentes quanto à visão que se pretende pela municipalidade, além de iniciativas que exploram a mobilização dos pichadores belo-horizontinos. Por fim, mais próximo de apontamentos e provocações, são apresentadas algumas considerações e listada a bibliografia consultada. 


\section{CIDADE E ORGANIZAÇÃO: OS VIESES OBJETIVO E SUBJETIVO IMPRESSOS NA GESTÃO URBANA}

As cidades são mais conjuntos múltiplos de ações coletivas, plenas de significados, construtoras de identidades e identificações do que conjuntos arquitetônicos, vias urbanas ou pessoas em movimento; assim percebidas, também são constituídas de muitas unidades organizativas (Fischer, I997). A cidade que nos interessa refletir é emergentemente explorada nos estudos organizacionais. A busca de trabalhos sobre a urbe nessa vertente levou a um conceito que evidencia o campo social, em detrimento de outros níveis pelos quais a cidade também possa ser analisada. A noção de organização-cidade (Fischer, I997; Fischer et al., I997; Mac-Allister, 200I, 2004; Saraiva, 2009; Saraiva \& Carrieri, 2012; Coimbra \& Saraiva, 2013) indica sua complexidade funcional e seu dinamismo simbólico, ao pontuar as interações subjetivas no espaço urbano e considerar uma identidade cultural.

Essa noção pressupõe para a urbe uma condição de permanente instabilidade, cujo equilíbrio é adornado por constantes reajustamentos e relativo controle (Mac-Allister, 200I). Ainda que no âmbito da cidade haja uma identidade conexa aos variados signos e símbolos passíveis de ser gestados, ela é, sobretudo, subjetividade e, portanto, pluralidade. A cidade é um mosaico composto por fragmentos, é mais plural que singular, difícil de se totalizar (Canclini, 2002; Pesavento, 2007; Magnani, 2008). Conforme Fischer et al. (I997), há um risco em definir conceitos genéricos, absolutos, presos a regras e padrões, e afastar conceitos mais específicos, dinâmicos ou relativos, abertos a diferenciações.

A tentativa de compreensão da cidade como organização evidenciou, além das questões sociais e da totalização de um objeto inerentemente fragmentado, uma lógica instrumental que se apresenta a partir dos processos de sua gestão. Se a cidade é uma organização, tem-se uma perspectiva de gestão que, assim, prevê controle e ordenamento, geralmente instrumentalizados por modelos de planejamento e gestão urbana, orientados por diretrizes políticas de uma administração pública que outrora se fez patrimonialista e burocrática, e, por ora, faz-se gerencialista nas principais capitais do Brasil. O aparato de uma administração pública essencialmente gerencial manifesta a configuração de novos formatos organizacionais, observados por parcerias público-privadas, alianças institucionais intra e intergovernamentais e ainda articulações trissetoriais, que, segundo Paula (2005), nem sempre correspondem aos anseios e às demandas sociais. 
A cidade referência para a gestão pública é orientada por políticas e ações estratégicas de um gerencialismo privado, cujas "integrações" e "inovações" pouco alcançam a diversidade de indivíduos e coletivos. Tal modelo já emprega tais critérios e tenta imprimir a perspectiva da governança pública, cuja capacidade de governo se baseia na cooperação entre os diferentes atores sociais, configurados em redes organizacionais (Kissler \& Heidemann, 2006). Da forma como se estabelece na administração pública gerencial, esse modelo de gestão preconiza sinergia e multiplicidade na personalização de gestores empreendedores que procuram criar ethos organizacional para a cidade (Fischer, I997).

Para Fischer (I997), a cidade assim governada logo se converte em cidade estratégica, estabelecendo organizações que mais servem aos planos e às estratégias locais e globais do que aos cidadãos. Nos estudos desenvolvidos sob o prisma organizacional, como se vê em Fischer (I997) e Fischer et al. (I997), o cenário da cidade estratégica é remodelado por diretrizes que unem ação social, viabilidade financeira, cooperação e publicidade: valores estéticos e funcionais que imperam e agem sobre o espaço natural e construído, exigindo um núcleo de competências em múltiplos saberes técnicos e humanos, criando novos designs, espaços competitivos e oportunidades de investimentos, sustentados por estruturas interativas, sistemas de alto desempenho e discursos de valorização da participação popular. Seguindo essa visão, dois eixos desenvolvidos sob a lógica capitalista se ampliam por meio das acepções de cidade global/mundial e cidade-mercadoria, determinantes de imagens-síntese e grandes projetos de revitalização urbana (Sánchez, 200I), apoiados em linhas temáticas ou "pontos fortes" da cidade, como os setores de turismo, história e cultura.

Para Lefebvre (2008), a estratégia global da cidade é mais uma reorganização das relações de produção e dos centros de decisão do que a simples venda de espaços. Nesse sentido, as próprias cidades são vislumbradas como produto, resultado do mercado de produção global do espaço. Para Sánchez (200I), a dinâmica de reprodução do capitalismo usa essa estratégia global e dá margem para a construção da cidade-mercadoria, criando imagens específicas e padronizadas para comercialização das cidades. Nesse prisma, as cidades tendem à homogeneização das formas de pensar e agir segundo aspectos provenientes de outros lugares do mundo, sejam eles próximos ou distantes (Santos, 20II).

As cidades estratégicas correspondem a uma forma ou pensamento único que não necessariamente decorre da hegemonia global (Maricato, 20II). Para Maricato (20II), a perspectiva cultural incide sobre a configuração urbana e emoldura a cidade-empresa-cultural designada pelo planejamento estratégico urbano em ações combinadas por agências de cooperação, instituições multilaterais e consultores internacionais, além dos representantes da gestão urbana 
local, cuja focalização citadina se desenrola sobre ações de marketing e visões culturais da cidade como espetáculo. O projeto de cidade se articula, assim, por três pareceres: I. cidade-mercadoria, também exposto por Sánchez (200I); 2. cidade-empresa, que se resume a uma unidade de gestão e negócios; e 3. cidade-pátria, representada pelo poder municipal como uma marca para identificação, fidelização e civismo (Maricato, 20II).

Esse modo de pensar a urbe propulsiona a realidade como consenso, sobre o qual o maior deles é expresso pela questão histórica relacionada às diferenças entre as classes sociais, agora reunidas sobre as objetividades do planejamento urbano gerencial (Maricato, 20II). O resultado presente, todavia, não se faz diferente do passado, em que pese o crescimento exponencial da "cidade ilegal”, segundo Maricato (20II), ou da informalidade como discutido por Carrieri, Maranhão e Murta (2009), em que se expandem contornos espaciais de segregação, pobreza, desigualdade e violência. Destarte, discorrer sobre a cidade como objeto dos estudos organizacionais pressupõe pensá-la sob conteúdo e forma interdisciplinares, levando em conta seus resultados e processos objetivos tanto quanto o cotidiano e a experiência de construção subjetiva. Mais do que uma sujeição às imposições globais, a complexidade local requer uma atenção aos aspectos singulares e plurais em cooperação entre as várias áreas do saber. Novas teorias organizacionais, desse modo, pressupõem novas teorizações sociais.

\section{CIDADE E PRÁTICAS ORGANIZATIVAS: ENTRE MECANISMOS E AGENTES SOCIOURBANOS}

No bojo dessa interpretação que compõe o referencial sobre a cidade como organização, o tema pode ir além de uma análise geográfica, transpondo as visões de gestão urbana e despontando sobre o imaginário e a prática de indivíduos e grupos que experienciam o cotidiano urbano. A compreensão de cidades e de suas práticas organizativas torna possível a constatação do pensar e agir sobre a urbe do ponto de vista dos diferentes agentes sociais, no uso de inúmeros recursos. Nos estudos organizacionais, a noção de práticas organizativas tenta superar dicotomias e fronteiras mais rígidas entre organização e ambiente, e, segundo Tureta e Araújo (20I3), remete à constante reconstituição ao longo do tempo.

A noção de práticas organizativas se integra à orientação da cidade, seguindo arcabouço teórico interdisciplinar e estudos clássicos revisitados por diversos autores em discussões contemporâneas. Refere-se à constante interação de indivíduos e grupos na práxis urbana, tendo em vista as construções sociais, 
históricas, econômicas, culturais e políticas. Inserindo-se na abordagem dos estudos organizacionais, abrange uma busca por entendimento dos modos como as práticas de planejamento, organização, controle, representação, resistência, recuperação e ressignificação, por exemplo, se configuram no âmbito da cidade, segundo o emprego de inúmeros mecanismos, recursos, modelos e instrumentos, além da integração dos diversos agentes, elementos e dimensões que tentamos, então, sintetizar.

As discussões propostas pela prática organizativa planejar refletem o direcionamento escolhido para o futuro da cidade, ao mesmo tempo que se vinculam de forma significativa e, por vezes, problemática aos cenários e às tendências globais (Sánchez, 200I). Os mecanismos de ação dessa prática contemplam algumas ferramentas de gestão e diretrizes governamentais, como o planejamento estratégico, as políticas públicas setoriais (habitação, saúde, comércio, serviços urbanos etc.), instituições normativas (como o Estatuto da Cidade), participação popular (conselhos e fóruns temáticos), entre outras. A implementação desses instrumentos pode considerar ainda instâncias simbólicas, como a história da cidade, a promoção de incentivos ou barreiras de uso do espaço urbano e o reforço da legitimação de um significado. O poder público, nos diferentes âmbitos e esferas, é o principal ator da prática planejar, ainda que os demais agentes sociourbanos planejem a cidade consciente e inconscientemente, uma vez que agem direta ou indiretamente no espaço e na dinâmica urbana.

A prática organizar concerne às atividades de ordenamento, conformação ou estruturação da cidade, segundo determinadas lógicas de produção econômica, social, urbana, estética etc. As discussões relacionadas a organizar a cidade se vinculam à complexidade socioeconômica e têm como características a inclusão, por vezes, precária, instável e marginal, e a exclusão de cidadãos, assim como a segregação por meio da requalificação do espaço urbano (Raichelis, 2006). Um dos principais mecanismos da prática de organizar a cidade se refere às diretrizes e políticas urbanas, expressas no conteúdo dos planos de ação governamental. Todos os atores organizam a cidade, geralmente, de acordo com certos objetivos e interesses, conforme necessidades e, sobretudo, segundo as relações de poder.

A inserção da prática organizativa controlar na cidade pressupõe o regulamento do espaço urbano por meio de mecanismos que visam a estabelecer a ordem e disciplinar os indivíduos a agir de acordo com certos padrões e princípios (Carrieri et al., 2009). O poder público é o principal responsável por controlar, ainda que outros mecanismos sejam criados pelos demais agentes. As discussões sobre essa prática se situam em torno das relações de poder, da divisão da sociedade em classes, dos conflitos entre grupos dominantes e dominados, dos movimentos sociais, dos aspectos ilegais, informais e ilícitos, da cumplicidade, corrupção e criminalidade, do caos e da ordem, entre outros. Alguns 
exemplos dessas temáticas refletem as questões do tráfico nas favelas e sua integração à cidade pelas medidas que instalam Unidades de Polícia Pacificadora nessas comunidades, assim como a instauração da especulação imobiliária e o manejo urbano.

Acerca da prática organizativa representar, sua inserção na cidade sugere atividades de produção de significações diversas, a partir das quais são possíveis distintas significações para o mesmo objeto. Ainda que a mídia exerça forte influência de representação por meio dos veículos de massa, que tendem a legitimar, reforçar ou arrefecer uma imagem criada por si ou pelos outros atores, cada ator sociourbano adota uma representação da cidade. As bases e os mecanismos de representação, segundo Canclini (2002), contemplam os sistemas de linguagem e comunicação (visual, escrita, oral); as diferentes formas de arte, história, memória e imaginário cultural, social e urbano; monumentos públicos e patrimônios tombados; entre outros elementos materiais e imateriais, cujo cerne preconiza, sobretudo, a dimensão espaçotemporal (local, regional, global; passado, presente e futuro) (Barreira, 2003).

A configuração da prática organizativa resistir no âmbito da cidade reflete atividades de negação de outras práticas organizativas; oposição ao determinismo empregado pelas instituições; e defesa de outras lógicas, impressas por crenças e valores divergentes do que é socialmente aceito. Existem diferentes formas, níveis e dimensões do resistir, cada qual emana dos inúmeros conflitos e contradições sociais (Britto \& Jacques, 2009). Em se tratando do espaço urbano, os atores negam a despolitização urbana, ou seja, a redução da participação e experiência das pessoas em relação à cidade, opondo-se à espetacularização da cidade e ao seu caráter meramente mercadológico, turístico, estratégico e consumista, ao mesmo tempo que defendem o uso do espaço urbano de forma igualitária e plural.

Sobre a inserção da prática organizativa recuperar, as principais discussões sugerem a restauração dos aspectos materiais para readequação do espaço urbano. É interessante saber a quem interessa e por que interessa, e o que constitui "recuperar". A preservação de memórias, a prevenção de desgastes, o combate à agressão visual, a melhoria da estética e qualidade de vida, a solução de problemas urbanos, a valorização de áreas específicas, a atração de investimentos, assim como a criação de identidades urbanas, são discursos associados à recuperação citadina. Alguns mecanismos de recuperação ocorrem por meio de revitalização histórica, pelos quais se pressupõem conteúdos a serem aproveitados para o direcionamento que se pretende para a cidade (Jayme \& Neves, 20Iо); pela reestruturação urbana, que sugere novos usos e significados para espaços e lugares da cidade (Sánchez, 200I); e pela gentrificação, sobre a qual são formuladas estratégias para requalificação do espaço por meio de ações que provocam mais segregação e exclusão social (Wacquant, 20Io). 
Por fim, a prática organizativa ressignificar confere novos significados a partir da reação de agentes sociourbanos aos movimentos e às tendências globais, seja em conflito ou cooperação. É oportuno saber a razão pela qual os significados mudam, seja pela transformação da sociedade, dos discursos compartilhados, mudança de interesses ou rompimento de instituições, ou, ainda, pela materialização do espaço físico e simbólico (Barreira, 2003). Assim como na prática de representação, ressignificar o espaço urbano pelos diferentes agentes pode envolver o emprego de imagens-síntese, assim como a operacionalização das demais práticas de planejamento, organização, controle, resistência e recuperação do/no espaço, as quais pressupõem novas formas de pensar e agir sobre a cidade.

No contexto das metrópoles contemporâneas e das práticas organizativas, em meio à interação instrumental e simbólica, cidades e cidadãos são percebidos, imaginados e comunicados, podendo ser autores da história ou simplesmente reprodução de um consenso compartilhado pela maioria (Canclini, 2002; Duarte, 2006). O espaço urbano das cidades, seus elementos, sua dinâmica e suas apropriações compõem uma das dimensões de manifestação ou expressão de diversos grupos sociais, meios empresariais, agentes governamentais, atores de interesse público e midiático, além de minorias culturais: "Isso se dá na medida em que ele abriga, registra e é fonte de representação, de identidade e de relacionamento entre os atores e a cidade, e vice-versa" (Ivo, 2007, p. I07).

Saraiva e Carrieri (2012, p. 547) sustentam que "a cidade é, inescapavelmente, seu povo”. É, assim, entendida como um espaço significado, construído com a participação humana e desenvolvido continuamente.

A cidade é mais do que um aglomerado de pessoas sobre um dado espaço geográfico; tem uma dinâmica processual coletiva alimentada continuamente por componentes individuais e culturais que implicam a construção de uma identidade local (Saraiva \& Carrieri, 20I2, p. 552).

No âmbito da cidade, há a ação de diferentes agentes, para o bem e para o mal, sendo importantes tanto medidas de controle e ordenamento quanto práticas autônomas e emancipatórias. Ante a paradoxal organização urbana, é cada vez mais difícil a integração e compreensão dos diversos modos de percepção e práxis. Perante os recursos, importa saber que a cidade é gente, independentemente de sua forma, posição geográfica ou função (Bernardi, 2006). A cidade é imagem e discurso revelados no espaço, interpretados nos planos individual e coletivo a partir da expressão de sentimentos, pertencimentos, utopias e esperanças (Pesavento, 2007). 


\section{ASPECTOS METODOLÓGICOS}

No presente estudo, norteado pela abordagem de pesquisa qualitativa, foram analisados os discursos que orientam práticas organizativas acerca da pichação na cidade de Belo Horizonte. Pesquisas de natureza qualitativa permitem compreensões acerca do fenômeno no seu contexto de ocorrência (Denzin \& Lincoln, 20II), além do aprofundamento de aspectos subjetivos (González Rey, 2005) e do arranjo de múltiplas técnicas de levantamento de dados (Linstead \& Grafton-Small, I990). Entendemos que essa abordagem é uma bricolage que possibilita a conjunção de representações específicas em um contexto complexo e preconiza a construção da realidade segundo reflexões e moldes variados e dinâmicos.

O contexto evidenciado, assim, partiu de investigação sobre o Projeto de Combate à Pichação (PCP), implementado pela Prefeitura de Belo Horizonte (PBH), pelo qual se chegou à constatação de um circuito mais amplo, engendrado pela percepção da sociedade civil, tanto em combate quanto em defesa da pichação. Como em um estudo de caso, inicialmente, foram levantados documentos oficiais sobre as ações governamentais no combate à pichação - o Planejamento Estratégico BH 2030 e seus desdobramentos -, assim como publicações acerca do Movimento Respeito por BH (MRpBH), no qual se vincula o PCP.

Em seguida, para conhecer a realidade sociourbana percebida pelos diferentes agentes, realizaram-se entrevistas individuais com nove sujeitos, entre gestores públicos municipais responsáveis pelo combate à pichação, indivíduos da sociedade civil participantes das ações do projeto municipal e representantes da pichação belo-horizontina. O tratamento dos dados foi efetuado por meio da análise do discurso francesa, pela qual se buscou a identificação e análise de aspectos e elementos discursivos segundo roteiro estruturado nos pressupostos de Faria (I998), Fiorin (I999), Maingueneau (I999) e Bakhtin (2006) sobre a análise do discurso.

Essa técnica de tratamento dos dados orienta um exame sistemático de textos e busca compreender os discursos, aprofundar o entendimento de suas categorias gramaticais em relação às ideologias e extrair os aspectos mais relevantes explícitos, implícitos e silenciados (Fiorin, 2005). A análise do discurso, assim entendida, configura-se na vertente francesa ou estruturalista, cuja abordagem articula as categorias linguísticas aos aspectos sócio-históricos e ideológicos, o que confere destaque para a relação entre linguagem e produção social (Orlandi, 2009). Nessa concepção, o discurso é a materialidade simbólica da produção social, uma categoria de linguagem que está diretamente conexa ao sujeito, que, por sua vez, está sempre ligado a uma ideologia.

Mais que uma análise linguística ou sociológica, a análise do discurso articula enunciados a partir de certos lugares sociais (Maingueneau, Barbosa, \& 
Lima, 2006) e permite a compreensão de sentidos produzidos em decorrência das diversas interações (Spink \& Medrado, I999). Dessa forma, a aplicação da análise do discurso ultrapassa uma simples análise verbal ao incluir aspectos não verbais e engendrar uma análise interacional. Seu diferencial está na evidenciação do sujeito no texto e na consideração da possibilidade de que o que as pessoas dizem nem sempre condiz com seus sentimentos e vivências (Godoi, 20IO).

Conforme o roteiro e as dimensões da vertente francesa, foram identificados e analisados os seguintes elementos: I. seleções lexicais - conjunto de palavras enunciadas em um discurso; 2. percursos semânticos estruturados a partir de temas e figuras - repetição contínua de elementos semânticos; 3. interdiscursividades - relação entre um conjunto de discursos ou um conjunto de unidades discursivas de um mesmo discurso; 4. discursos principais - processos cognitivos de produção social de textos; 5 . reflexão e refração linguísticas - manutenção do sentido socialmente estabelecido e reinterpretação dos sentidos conforme referenciais dos enunciadores (ressignificação de temas nos discursos); 6. aspectos ideológicos combatidos e defendidos - em termos discursivos, intenção do texto ou posição imanente a um dado enunciado discursivo; e 7. posicionamentos discursivos em relação aos discursos hegemônicos na sociedade - contraposição entre o discurso do enunciador e o discurso hegemônico da sociedade em termos dominantes e marginais.

Os fragmentos discursivos destacados para apresentação dos resultados de pesquisa compreendem categorias que se referem aos pressupostos das práticas organizativas norteadoras da pichação na cidade. Para fins de compreensão da análise dos dados, termos e frases destacados em negrito se referem aos aspectos e elementos que serão analisados, para os quais uso o destaque em itálico quando da sua retomada analítica.

\section{BH 2030: A CIDADE TOMADA PELA GESTÃO ESTRATÉGICA}

As origens e a extensão do combate à pichação em Belo Horizonte, segundo documentos e relatos, evidenciam diferentes ângulos de organização da cidade e permitem a análise de diferentes práticas organizativas. $O$ enfrentamento decorre da década de I990, inicia-se pelas vias político-partidárias, fundamenta-se na legislação e na busca por compreensão e diálogo, e avança para o aspecto estético e cívico se sustentando pelo controle e ordenamento do espaço urbano por meio de um conjunto de leis antipichação. Atualmente, as políticas de combate à pichação seguem as marcas da profissionalização da administração pública, 
conforme os pressupostos do Planejamento Estratégico BH 2030 e do modelo de gestão estratégica denominado $\mathrm{BH}$ Metas e Resultados, que se divide em I2 áreas, dentre as quais, na área cidade sustentável, origina-se o programa MRpBH e deste a formatação do PCP, implementado na cidade desde 2009.

Pelo desdobramento do plano se reconhece a busca de integração das ações de combate à pichação a outros recursos e agentes que visam a legitimar a organização da cidade segundo ordenamentos e critérios instrumentais, tais como a gestão por resultados, mobilização de parcerias e trabalho em rede e definição de responsabilidade gerencial. Da sua leitura técnica, em termos urbanísticos, pouco se abstrai a ideologia que será seguida pelos gestores municipais, tanto quanto é possível perceber na descrição do programa MRpBH.

(O०I) O movimento busca organizar o espaço urbano, de forma colaborativa e democrática, fazendo valer as recentes modificações incorporadas ao Código de Posturas do município entre outras legislações e, em especial, aquelas que se referem ao meio-ambiente, ao direito à paisagem e à Lei $\mathbf{N}^{\circ}$ I0.059, sancionada pelo Prefeito em 28 de dezembro de 2010 (SMSEG, 2013, p. I).

O texto (০০I) explicita as intenções impressas no programa municipal para organizar o espaço urbano e não se deixa esquivar dos meios para alcançar o resultado esperado. Os léxicos colaborativa e democrática, e a referência às figuras e temáticas, tais como Código de Posturas, meio-ambiente, direito à paisagem e Lei n. 10.059 (referente às políticas municipais de antipichação) expressam estratégias de persuasão discursiva e destacam o valor conferido ao aspecto legal para controle e organização da cidade. Uma vez estabelecidas as bases de atuação, também afirma que a legislação por si não é suficiente para garantir o ordenamento que se diz adequado à cidade, conforme relato do texto (००2): "A legislação, por si só, não funciona. Não adianta nada você ter lei antipichação, se você não tem o procedimento que traz aí algo diferente" (representante da PBH e gestor do $\mathrm{MRpBH} / \mathrm{PCP})$.

O fragmento (002) indica uma interdiscursividade e deixa subentendido que é preciso pensar e organizar a cidade integrando outras formas de fazer valer a legislação antipichação. Os léxicos não funciona e procedimento expressam o aspecto de instrumentalidade do discurso e sugerem que a cidade precisa ser funcional e seguir uma lógica processual em detrimento de outros aspectos (implícito pressuposto). O procedimento que prevê algo diferente compreende a inclusão de diversos atores no cenário de enfrentamento à pichação para organização formal da cidade e, conforme expresso por Fischer (I997), denota o ethos organizacional criado para a cidade estratégica (implícito subentendido). $\mathrm{Na}$ 
configuração construída pelo governo da cidade, é expressa a articulação entre os poderes públicos e a sociedade civil a partir de órgãos dos âmbitos municipal e estadual e entes privados, reconhecidos no segundo e terceiro setores.

O arranjo em rede potencializa a mobilização de outros atores para tratamento da pichação como prática não desejada na cidade. Nesse esteio, o governo da cidade orienta representações de quem deve fazer parte das questões sociais e urbanas e quem deve ser excluído. É interessante perceber a cognição relacionada às três ações estratégicas do projeto: despiche, sensibilização e repressão, que compreendem, respectivamente, ações de limpeza urbana, conscientização social acerca da criminalidade da pichação e coerção, e punição dos pichadores (SMSEG, 20I3).

(004) A pichação acaba sendo um trabalho assim de insistência, porque cada vez que você limpa e o outro picha, quer dizer, quem é mais resistente, não é? Em limpar ou em pichar (representante da $\mathrm{PBH}$ e gestor do $\mathrm{MRpBH} / \mathrm{PCP}$ ).

(005) Por exemplo, para executar essas ações a gente precisa muito da Secretaria Municipal de Educação, porque essas ações são executadas prioritariamente em escolas. E as escolas são um dos grandes demandantes, nós temos Guardas Municipais em todas as escolas. E a gente tem o BI, que é o boletim de intervenção, que a gente registra ali as infrações. [...] Nós precisamos da BHTRANS muitas vezes para poder fazer uma intervenção no trânsito para fazer nosso trabalho; o Guernica com a questão dos fóruns de discussão, de diálogos entre pichação e grafite; e principalmente nós temos aqui outros órgãos como a Polícia Civil, através da Delegacia de Meio Ambiente... E a Polícia Militar, que tem o Olho Vivo, que é uma das estratégias da Gestão Qualificada, de videomonitoramento (representante da PBH e analista do PCP).

O fragmento (004), interdiscursivamente, estabelece uma relação de controle e resistência, expressando a insistência da $\mathrm{PBH}$ em limpar os lugares pichados (despiche) e, de outro modo, a resistência dos pichadores em deixar suas alcunhas pela cidade. No texto (005), há a expressão de alguns percursos semânticos, como o da educação infantil, expresso pela seleção lexical ações são executadas prioritariamente em escolas. Um segundo percurso se refere à mobilização de outros entes, entre os quais a BHTRANS, que confere ajuda para o trabalho de conscientização social feito por meio de intervenção urbana (sensibilização). O terceiro caminho aponta para a figura do Projeto Guernica (contempla, por meio do grafite, atividades de arte urbana e cultura de rua nos grupos sociourbanos), destacando 
um percurso que explicita os fóruns de discussão e os diálogos entre pichação e grafite. Destaca-se, ainda, o percurso da vigilância e penalização no apontamento da Polícia Civil e Delegacia de Meio Ambiente (repressão).

Nesses textos, os caminhos seguidos pelo projeto da PBH sustentam o discurso social hegemônico implícito nos relatórios do planejamento estratégico, isto é, a visão de futuro que se pretende para a cidade e seus cidadãos, com os quais se têm modos e tratamento específicos. É possível perceber a intencionalidade dos enunciadores em reforçar a pichação como uma prática que precisa de intervenção, segurança e punição nas escolas, que têm a constante presença de Guardas Municipais e a coerção dos Boletins de Intervenção; e nos espaços públicos, pela figura da Polícia Militar, dos mecanismos de vigilância e gestão estratégica (Olho Vivo e Gestão Qualificada).

Embora o projeto municipal determine três ações estratégicas (despiche, sensibilização e repressão), pelas quais demonstra alguns interesses de participação popular, além de aproximação e diálogo com os jovens infratores, os depoimentos sugerem que o projeto também corresponde a uma tentativa de controle sobre o comportamento social de crianças, adolescentes, jovens e adultos na cidade, além de práticas organizativas de representar, que orientam a estética da urbe. Os discursos expressam a valorização do cumprimento da legislação e, ao travestirem-se de civismos, talvez mais representem o interesse instrumental pela cidade e a produção de respostas à parcela da sociedade que propulsiona o ideário contra a pichação. O governo da cidade, assim, tanto orienta as representações de combate à pichação como é pressionado para enfrentar o fenômeno segundo os vários modos de fazer, pelos quais imperam os instrumentos de controle sobre as práticas de organização da cidade e se instituem agentes sociourbanos de legitimação estratégica.

\section{INTERESSES PÚBLICOS E LEITURAS SOCIAIS}

A configuração estratégica preconizada pelo programa municipal evidencia as práticas de representar e controlar a partir de suas interfaces coletivas. Por meio dos vínculos para o combate à pichação na cidade, pudemos constatar vários objetivos e perspectivas para a concretização das articulações entre governo e sociedade, além de algumas especificidades produzidas pelas orientações expressas nas três ações estratégicas, sobretudo na ação de despiche, que emolduradas em evento de conscientização, com atividades lúdicas e de cunho social, refletem o que Maricato (20II) denotou para a espetacularização da cidade. Os 
depoimentos destacam as percepções e os objetivos dos diferentes indivíduos vinculados a uma instituição privada de ensino superior, a uma associação esportiva e a uma empresa ligada à indústria e comercialização de materiais químicos, as quais participaram das ações de despiche no Complexo da Lagoinha e no Conjunto Arquitetônico da Pampulha, lugares emblemáticos para Belo Horizonte e alvos de pichação.

(oo6) O que houve foi uma sinergia entre o programa em si, do Movimento Respeito por BH, com também uma outra apresentação, que foi do programa de gestão social que estava sendo introduzido no Centro Universitário de Belo Horizonte, o UNIBH. [...] Porque quando você pensa na questão da estrutura pública, você trabalha de uma forma, assim, com vários fatores, várias gerências, vários interesses (professor do centro universitário e servidor da PBH).

O fragmento discursivo (oo6) indica os motivos que uniram o programa de governo e o programa de gestão social do centro universitário para o combate à pichação. Além da sinergia, os léxicos fatores, gerências e interesses sugerem o percurso semântico da multiplicidade de aspectos que corroboraram a parceria. A estrutura pública é tema referenciado no enunciado como uma composição que demanda o trabalho colaborativo (implícito subentendido). O texto reflete o discurso hegemônico ao evidenciar uma postura consensual dos organizadores do projeto ante os demais atores sociais. A participação da comunidade acadêmica na ação de despiche é descrita no texto (007).

(००7) [...] o professor Rogério é uma pessoa muito engajada nas questões sociais, ele trabalha na prefeitura, obviamente ele tem que ter essa visão, é um excelente professor, e ele realmente trouxe uma proposta bacana. A minha turma ficou muito empolgada, foi um trabalho muito prazeroso. Não só na questão, como eu te disse anteriormente, de revitalizar, fazer parte desse meio, mas como o nosso entrosamento também, contribuiu muito pra nossa convivência fazer parte desse trabalho (aluna do centro universitário).

O processo de produção cognitiva exposto no fragmento (007) reconta a história a partir da representação do professor, que aparece como personagem intermediador entre a instituição de ensino e a prefeitura. No relato, o engajamento em questões sociais e o desempenho em sala de aula são temáticas usadas para justificar a proposta de ação social. A entrevistada tenta demonstrar os aspectos positivos da atividade, evocando uma imagem de sociabilidade entre os indivíduos da 
turma (contribuiu muito pra nossa convivência), além da questão da contribuição social e cooperação com um serviço público (não só na questão da revitalização) que, juntas, representam ícones de urbanidade. As seleções lexicais minha turma ficou muito empolgada e foi um trabalho muito prazeroso também engrandecem a proposta de despiche da cidade, confirmando a aceitação da visão compartilhada pela municipalidade.

(o०8) Foi na realidade uma conjunção de fatores. Uma pessoa falou assim vamos ter o projeto de despiche. [...] A assessora entrou em contato e nós achamos a ideia genial e absolutamente dentro dos nossos objetivos sociais (presidente da associação esportiva).

O enunciado (০o8) também remete ao percurso semântico da conjunção de fatores para a consecução de parceria entre uma associação esportiva de ciclismo e a prefeitura na organização da cidade e no combate à pichação. O enunciador expressa a congruência dos objetivos da $\mathrm{PBH}$ com os objetivos sociais do grupo, o que reforça que o discurso da ação social também faz parte da ideia do coletivo de ciclistas para intervenção urbana. O discurso (০o9) também torna a mensagem de cooperação evidente, ao associar a necessidade da $\mathrm{PBH}$ em obter parcerias para projetos sociais. O enunciador afirma que a demanda originou-se da necessidade de recursos para a limpeza das pichações na cidade. Uma divergência de objetivos é expressa na sintaxe não agrega à nossa imagem, já que o enunciador também deixa claro que alguns públicos não são interessantes para o uso dos recursos da organização.

(০०9) [...] ele [secretário municipal] precisava de uma indústria de tinta para fazer esse serviço [de despiche]. Eu fiz o contato com a diretoria da empresa, a gente já teve alguns projetos sociais, e a empresa topou fazer. [...] Quando a empresa entende que aquele projeto é viável, às vezes não é viável financeiramente, mas ele é viável por imagem. Tem coisas que as pessoas apresentam para a gente que não agrega à nossa imagem devido ao público que ele vai atingir. Para a gente alguns públicos não são interessantes (representante da empresa de tintas e produtos químicos).

A interdiscursividade relacionada à doação de recursos para a limpeza urbana se faz presente no discurso da ação social, veiculada por meio do patrocínio a intervenções no espaço urbano. Pela mensagem de segregação de possíveis parceiros e declaração de interesses de promoção da imagem, são expressos os 
discursos do consumo e do marketing social, que se sobrepõem ao da ação social. O que sobressai dessa integração entre a prefeitura e o setor empresarial, mais do que o percurso semântico da ação social pública ou responsabilidade social empresarial, são fatores políticos e econômicos, em que se promovem o governo e a gestão da cidade. Igualmente, a empresa patrocinadora veicula sua marca para a sociedade, que pensa contribuir com uma causa social. O fragmento (oIo) sugere uma percepção mais crítica em relação aos arranjos configurados para a organização da cidade:

(ого) A prefeitura, como qualquer órgão público democrático, tinha que fazer assembleias, uma discussão diretamente com os envolvidos, com pichador, com grafiteiro, com polícia, com o ministério público, para saber realmente qual é o impacto não só visual de que o picho tem para cidade. [...] Geralmente, a prefeitura chega até você quando ela já está com tudo armado, isso é prejudicial para todo mundo. [...] Se a gente não partir para o diálogo para saber realmente quem está mais incomodado e quais são as partes mais afetadas (aluno do centro universitário e ex-pichador).

O fragmento (оIо) marca a ausência de uma discussão sobre a pichação e deixa explícita a necessidade de uma assembleia popular. A interdiscursividade das relações de poder está presente entre os diferentes grupos sociais que se conectam pela prática na cidade (pichador, grafiteiro, polícia, ministério público, prefeitura, sociedade), e a forma de atuação da prefeitura, conforme a seleção lexical, já está com tudo armado. Também há uma mensagem ideológica na sugestão de que existem indivíduos ou grupos mais incomodados e mais afetados em relação à pichação, sugerindo um discurso que defende diálogo sobre o tema e contrapondo a posição hegemônica sobre a criminalidade da pichação e o respeito ao espaço público, determinado verticalmente pela municipalidade.

No exposto, uma gestão horizontal é infame, feita de articulações tendenciosas que almejam conferir uma reorganização das relações de produção (Lefebvre, 2008), além de agentes legitimadores das orientações visuais pretendidas para o espaço urbano (Canclini, 2002). A ideia de construção conjunta e gestão pública se resume a um formato de cooperação, pelas vias de projetos sociais, em que os agentes apenas contribuem na execução das ações previamente estabelecidas com os atores institucionais. Conforme sustentam Fischer et al. (I997), ação social e cooperação são compromissos da cidade estratégica, assim como os discursos de valorização da participação social. Os recursos ora empenhados e ora omitidos reforçam a noção de que as práticas organizativas de controle pressupõem um regulamento para a cidade (Carrieri et al., 2009), e as práticas 
organizativas de resistir, segundo Britto e Jacques (2009), emanam dos inúmeros conflitos e das contradições sociais. Discutiremos a seguir como a pichação pode significar resistir e ressignificar como prática organizativa na cidade.

\section{PICHO, UM "MOVIMENTO"?}

As percepções e concepções compartilhadas sobre a pichação evidenciam assimilações sociourbanas a partir da prática e das interações por ela permitidas aos pichadores e a seus representantes, consciente ou inconscientemente. Destacamos, neste tópico, alguns elementos que cercam sua essência e apontam iniciativas que orientam um movimento alternativo conexo à pichação em Belo Horizonte, cujo cerne revela aspectos característicos da composição coletiva entre os pichadores, suas interações com outros agentes sociourbanos, além de interpretações concernentes à sociedade e ao governo municipal.

Os relatos permitiram constatar interações que permeiam diferentes coletivos, entre os quais pichadores, grafiteiros e rappers do movimento hip-hop e pesquisadores. Os discursos de resistência por meio da pichação são conferidos por quem a entende como um meio de manifestação política, entre outras percepções. A prática, assim, se torna uma ferramenta de oposição às políticas públicas que estabelecem formas de segregação da cidade, fortalecem a desigualdade social e desconsideram as interações existentes. Do mesmo modo, contrapõe a sociedade e as normatizações aceitas pelos grupos dominantes.

(OII) Isso é uma ferramenta que a gente tem de cutucar o sistema, de fazer eles olharem pra nós. É igual o duelo, a resistência, tem que ser assim. Ah, não gosta não? Ela vai existir, ela não vai parar não (representante de pichação e grafiteiro).

(OI2) Picho é a forma menos agressiva e menos violenta de reivindicar o que a gente quer e o que que é a cidade. É a chaga da cidade, o que que o picho representa pra gente, fraga (representante de pichação, grafiteiro e rapper).

O texto (OII) indica a figura do duelo de MCs, um coletivo ligado ao movimento hip-hop em Belo Horizonte, como agente de resistência contra o sistema, e a pichação, uma ferramenta capaz de tensionar conflitos e despertar a atenção do poder público para os anseios políticos e culturais dos grupos urbanos (implícito pressuposto). A seleção lexical ela vai existir, ela não vai parar não reafirma a vivência da pichação como manifestação sociourbana, que independe dos sentimentos 
por ela provocados (gostar ou não). Conforme o texto (OI2), a pichação é a forma menos agressiva e menos violenta de reivindicar o que é a cidade. Ao interpretá-la como uma chaga, o implícito subentendido é que o enunciador também evoca seu sentido de dano à cidade, em seus aspectos abstratos ou concretos.

O sentido político da pichação é expresso no fragmento discursivo (OI3), que também a assimila como forma de identidade juvenil, liberdade de expressão e ocupação da cidade. O percurso semântico empregado por meio dessas temáticas aponta para o discurso de pertencimento, uma vez que o jovem não se beneficia de tudo que é feito na cidade e a pichação se torna um meio de apropriação individual. O implícito subentendido é que a cidade (suas ações, intervenções, os prédios, centros culturais e toda a sua materialidade no espaço urbano) não é pensada e organizada para todos. Interdiscursivamente, a pichação denota a relação de mudança alternativa e necessária ao pertencimento de quem se sente excluído do contexto urbano e, por meio dela, encontra uma forma de expressão de poder.

(OI3) A pichação é uma forma de identidade juvenil e ela é assimilada por determinados jovens, como uma liberdade de expressão, de ocupação da cidade que é dele também. Na visão dele, ele não sente beneficiado com todas as ações que acontecem na cidade, com as intervenções, os prédios, centros culturais e tudo, e aí eu acho que a pichação veio um pouco para reformar isso, sabe assim?, uma forma de expressão de eu posso (aluno do centro universitário e ex-pichador).

O aspecto político também é evidenciado sobre o mote de responsabilização, valores e ética dos pichadores, conforme os fragmentos discursivos (OI4) e (OI5).

(or4) O pichador ele tem uma coisa da responsabilidade, né?, assim como ele se apropria daquele espaço, ele se apropria daquele nome e aquele nome o representa. Eles têm uma coisa, assim, os valores deles, as coisas do movimento deles, é muito importante e é natural. Talvez por isso eu tô dizendo que tem uma forçação do respeito por parte da prefeitura, mas a ética, ela é uma questão pro picho (pesquisadora de pichação).

(OI5) Não tô nem falando assim: "Ah, pichador não comete crime". Tô falando que assim, se você comete um crime, cê paga pelo crime, se você faz o picho, cê paga por ele, sabe? [...] Porque nem os pichadores não querem deixar de pagar pelo que eles fazem. O que eles questionam é assim: tem que ser saco de pancada mesmo? E tem que ir pra cadeia? (pesquisadora de pichação). 
O texto (OI4) apresenta o percurso semântico da ética do picho para evidenciar que há responsabilidade e valores por aqueles que praticam a pichação. Os modos de apropriação do espaço e de um nome de representação refletem a lógica dos pichadores e a natureza do movimento do picho, pela qual diferem e se contrapõem à lógica do programa da prefeitura (implícito subentendido), em que se constata um equívoco (forçação) na representação da palavra respeito. O mesmo enunciador, no discurso (OI5), evidencia sua concordância acerca da criminalidade da pichação e a disposição dos pichadores em responder juridicamente pelo crime cometido. A responsabilização pela prática remete à ética do picho, compartilhada por aqueles que participam do movimento, que, de outro modo, resiste aos abusos e às distorções cometidos pelas ações de combate à pichação. Esses aspectos são expressos pela metáfora ser saco de pancada, que conota o abuso empregado pelas autoridades policiais sobre os pichadores, e pela menção implícita à prisão dos "piores de Belô", grupo dos pichadores mais atuantes em BH, detidos em 2008 pelo crime de formação de quadrilha por meio da operação policial BH Limpa e do programa MRpBH.

As interpretações discursivas indicam oposição explícita e implícita às ações do programa da prefeitura, à conduta policial e ao pensamento dominante sobre a pichação e os pichadores. Ao indicarem a força política do picho, os entrevistados tentam expressar sua capacidade de resistência ao modelo de governo e organização da cidade, posicionando-se como agentes sociais e urbanos, e, indiretamente, exprimindo um apelo por reconhecimento individual e coletivo. A organização de um grupo que expressa um sentido ético particular se faz por esses objetivos e pela oposição à violência e estigmatização dos pichadores pelo governo, pela justiça e pela sociedade.

A refração dos sentidos socialmente aceitos, segundo os referenciais daqueles que seguem e defendem a lógica da pichação, também é apreendida e parece não expressar deferência aos valores e posicionamentos dos demais agentes sociourbanos, provocando reproduções de alguns dilemas sociais e deslocamentos de estigmatizações. Observa-se pelos discursos que se trata de múltiplas posições, em distintos níveis de significação, a respeito do que o picho representa. A rigor, só se pode falar em movimento social se a visão é ampliada, de maneira a contemplar a possibilidade de que a pluralidade associada à pichação possa ser tomada como facetas de um mesmo fenômeno. Em outras palavras, "o espaço de cidadania é ocupado em movimentos coletivos num jogo de dispersões e individualidades, revelando um impulso de buscar a significação do mundo e, também, significar-se" (Fernandes, 20II, p. 24I). 


\section{CONSIDERAÇÕES FINAIS}

Neste artigo, buscamos analisar os discursos que orientam práticas organizativas relacionadas à pichação em Belo Horizonte. As discussões engendradas referenciam temáticas complexas e antagônicas, das quais muito se pode refletir e, talvez, pouco responder ou concluir. Analisar os discursos se tornou uma indicação de fenômenos e conflitos sociourbanos, construídos histórica e culturalmente e inflamados nos dias de hoje, assim como uma provocação a debates relacionados a ações públicas, equívocos e precipitações sociais. Sob outro ângulo, também estão presentes as reproduções e os deslocamentos, já que, assim como são constatadas ressignificações sociourbanas, também se verificam tipificações estigmatizantes e segregacionistas entre quem pertence ou não às práticas organizativas na cidade. Ainda, a compreensão da existência de uma ética particular pode aprofundar moralismos ou introduzir novos preconceitos na sociedade, já repleta de dilemas sociais.

Expomos tais percepções com base no analisado discursivamente, apreendido e vivenciado com os sujeitos de pesquisa. Estes, em alguns momentos, fizeram imposições maniqueístas diante de um contexto emblemático e paradoxal, como se apenas houvesse um lado a defender e outro a combater. Não nos esquivamos, no entanto, de algumas considerações sobre os discursos que orientam práticas organizativas, pelas quais o presente estudo evidencia modos de organização na e da cidade para além dos instrumentos e das técnicas de planejamento urbano empregados no âmbito da administração pública. Também se emolduram diferentes configurações entre indivíduos e grupos que vivenciam a cidade, pelos quais as interações sociourbanas remontam a novas práticas de organização, capazes de ressignificar a dinâmica que orienta a cidade por mecanismos governamentais, mas vão além disso com subjetivações que emanam das relações de poder, hegemônico ou de resistência.

No que concerne ao combate à pichação, os discursos evidenciam práticas de planejar, controlar, organizar, representar e recuperar a cidade, como se uma única visão citadina e seus cidadãos precisassem ser formalmente ordenados e articulados por estratégias gerenciais (Maricato, 20II). Tal visão chega a ser compartilhada ou reproduzida pela sociedade, embora às mesmas práticas organizativas se integrem interesses e objetivos distintos, pelos quais a cidade, como asseveram Magnani (2008) e Pesavento (2007), torna-se o que de fato ela é, receptáculo de múltiplas visões e, ainda, espaço significado, edificado continuamente pela sua população (Saraiva \& Carrieri, 20I2). O pluralismo, então, é o que engatilha as práticas de resistir e ressignificar, que, em relação à pichação na cidade, pouco avançam em configurações efetivamente múltiplas. 
A cidade, como espaço de muitos lugares, individualidades e coletividades, decorre de práticas organizativas cujos simbolismos permeiam estratégias para mostra em uma vitrine global (Sánchez, 200I; Lefebvre, 2008; Santos, 20II). Assim, aspectos locais e globais são tensionados a partir dos planos de governo e, no caso da capital mineira, como discutido por Raichelis (2006) e Carrieri et al. (2009), também seguem sob controle de representações sociourbanas e reinvenções subversivas do ordenamento planejado. Os discursos e a legitimidade de organização da cidade são conferidos pelas leituras institucionalizadas, baseadas, principalmente, no legalismo dos programas de governo, baseado em estatutos, códigos de conduta e demais instrumentos e modelos oriundos de um gerencialismo público. A politização relacionada aos aspectos urbanos é aclamada entre coletivos e evoca para a dinâmica urbana, além de posições críticas, escapes subversivos.

O presente estudo implica um novo olhar sobre a urbe na análise organizacional e emoldura conexões interdisciplinares, assim como contribui para o conhecimento da dinâmica urbana ligada à pichação. O saber acerca das interconexões existentes nessa dinâmica revela subsídios para um novo pensar e agir sobre a urbe, o qual se faz mais crítico e reflexivo diante de significações e transformações sociourbanas. Pesquisas relacionadas às temáticas aqui referenciadas podem se aprofundar no exame de identidades urbanas, na análise organizacional dos grupos de pichação, combinada à observação das ressignificações e invenções de novas tipificações, e ainda investigar os efeitos das práticas organizativas sobre a dinâmica e o espaço urbano.

\section{DISCOURSES, ORGANIZATIVE PRACTICES AND GRAFFITI IN BELO HORIZONTE}

\section{ABSTRACT}

The city has traditionally been viewed in its administration under the functionalist perspective, to be understood as professional field or object of public administration and urban management. However, studies concerning cities in a nonfunctionalist perspective have become increasingly applicant mainly within a perspective which focuses on urban complexity and evokes the organized social life of oppressed individuals and groups in different social environments. In this article, we analyze discourses that guide organizational practices related to graffiti in Belo Horizonte (Brazil), which was done through a qualitative study based on discourse analysis. Apart from research in official documents on government 
actions to combat graffiti, individual in-depth interviews were conducted with nine subjects, among municipal administrators responsible for fighting against graffiti, civil society participants of the actions of municipal project, and representatives of graffiti from Belo Horizonte. Data analysis was performed by French discourse analysis, in which we sought to identify and analyze discursive aspects and elements following a script consisting of: I. lexical selections; 2. semantic paths; 3. interdiscursivity; 4. major discourses; 5 . linguistic reflection and refraction; 6. defended and fought ideological aspects; and 7. discursive positions in relation to the hegemonic discourses in society. Main results suggest that the city government both directs representations of the fight against graffiti and is pressed to face the phenomenon according to several approaches , by which prevail control instruments over the organizational practices of the city, and establishing socio-urban agents of strategic legitimation. We conclude that the public administration is re-signified by different social actors, in particular by the taggers, who adopt a kind of graffiti code of ethics, which antagonizes the city government program, the police conduct and the dominant thinking on the graffiti and taggers, manifesting their position through graffiti.

\section{KEYWORDS}

City. Organizational Practices. Discourse. Graffiti. Urban Management.

\section{DISCURSOS, PRÁCTICAS ORGANIZATIVAS Y GRAFFITI EM BELO HORIZONTE}

\section{RESUMEN}

La ciudad ha sido considerada tradicionalmente en la administración bajo la perspectiva funcionalista, al ser entendida como campo de actuación profesional u objeto de la administración pública y la gestión urbana. Sin embargo, los estudios que se ocupan de las grandes ciudades en una perspectiva no funcionalista se han vuelto cada vez más demandantes, principalmente a partir de una visión que se centra en la complejidad urbana y evoca la vida social organizada de individuos y grupos oprimidos en diferentes entornos sociales. En este artículo se analizan los discursos que orientan las prácticas organizativas relacionadas con el graffiti en Belo Horizonte, que se hizo a través de un estudio cualitativo basado en el análisis del discurso. Además de la investigación en los documentos oficiales sobre las acciones del gobierno para combatir el graffiti, entrevistas 
individuales en profundidad se realizaron con nueve sujetos, entre los administradores municipales responsables de la lucha contra el graffiti, individuos de la sociedad civil que participan de las acciones del proyecto municipal y representantes del graffiti de Belo Horizonte. El análisis de datos se realizó mediante el análisis del discurso francés, en el que hemos tratado de identificar y analizar las cuestiones y elementos discursivos según el guión constituido por: I. selecciones de léxico; 2. los recorridos semánticos; 3. las interdiscursividades; 4. los discursos más importantes; 5. reflexión y refracción lingüísticas; 6 . aspectos ideológicos combatidos y defendidos; y 7. las posiciones discursivas en relación a los discursos hegemónicos en la sociedad. Los principales resultados sugieren que el gobierno de la ciudad no solo orienta la representación en cuanto a la lucha contra el graffiti como también sufre presión para hacer frente al fenómeno de acuerdo a las diversas formas de hacer, por lo que prevalecen los instrumentos de control sobre las prácticas organizativas de la ciudad y el establecimiento de agentes socio-urbanos de legitimación estratégica. Llegamos a la conclusión de que la administración pública se re-significa por los diferentes actores sociales, en particular por los grafiteros, que adoptan una especie de ética del graffiti, que es antagonista del programa del ayuntamiento, de la conducta de la policía y del pensamiento dominante sobre el graffiti y los grafiteros, que manifiesta su posición por medio del graffiti.

\section{PALABRAS CLAVE}

Ciudad. Prácticas organizativas. Discurso. Graffiti. Gestión urbana.

\section{REFERÊNCIAS}

Bakhtin, M. (2006). Marxismo e filosofia da linguagem (8a ed.). São Paulo: Hucitec.

Barreira, I. A. F. (2003). A cidade no fluxo do tempo: invenção do passado e patrimônio. Sociologias, 5(9), 3I4-339.

Bernardi, J. L. (2006). Funções sociais da cidade: conceitos e instrumentos. Dissertação de mestrado, Pontifícia Universidade Católica do Paraná, Curitiba, PR, Brasil.

Britto, F. D., \& Jacques, P. B. (2009). Corpocidade: arte enquanto micro-resistência urbana. Fractal: Revista de Psicologia, 21(2), 337-350.

Canclini, N. G. (2002). Cidades e cidadãos imaginados pelos meios de comunicação. Opinião Pública, 8(I), 40-53.

Carlos, A. F. A. (2008). A cidade (8a ed.). São Paulo: Contexto.

Carrieri, A. P., Maranhão, C. M. S. A., \& Murta, I. B. D. (2009). Crítica ao manejo humano em Belo Horizonte. Revista de Administração Pública, 43(6), I315-1342. 
Coimbra, K. E. R., \& Saraiva, L. A. S. (2013). Territorialidade em uma organização-cidade: o movimento Quarteirão do Soul. Gestão \& Regionalidade, 29(86), 34-46.

Denzin, N. K., \& Lincoln, Y. S. (20II). The Sage handbook of qualitative research (4rd ed.). Thousand Oaks: Sage.

Duarte, F. (2006). Rastros de um rio urbano: cidade comunicada, cidade percebida. Ambiente \& Sociedade, 9(2), I05-122.

Faria, A. A. M. (1998). Discurso e leitura, semântica e argumentação em Germinal. In I. L. Machado, A. R. Cruz, \& D. Lysardo-Dias (Orgs.). Teorias e práticas discursivas: estudos em análise do discurso. Belo Horizonte: UFMG.

Fernandes, E. M. F. (20II). Pichações: discursos de resistência conforme Foucault. Acta Scientiarum. Language and Culture, 33(2), 24I-249.

Fiorin, J. L. (1999). Semântica e análise do discurso. In H. Mari, S. Pires, A. R. Cruz \& I. L. Machado (Orgs.). Fundamentos e dimensões da análise do discurso. Belo Horizonte: UFMG.

Fiorin, J. L. (2005). Linguagem e ideologia (8a ed.). São Paulo: Ática.

Fischer, T. (I997). Gestão contemporânea, cidades estratégicas: aprendendo com fragmentos e configurações do local. In T. Fischer (Org.). Gestão contemporânea: cidades estratégicas e organizações locais (2a ed., pp. 13-23). Rio de Janeiro: FGV.

Fischer, T., Teixeira, A., Loiola, E., Santos, J. N., Heber, F., Dantas, M., Siqueira, M. L., Santana, M., McAllister, M., Miguez, P., Moura, S., \& Dias, T. (I997). A cidade como teia organizacional: inovações, continuidades e ressonâncias culturais. Revista de Administração Pública, 31(3), 74-88.

Godoi, C. K. (20I0). Perspectivas da análise do discurso nos estudos organizacionais. In A. B. Silva, C. K. Godoi \& R., Bandeira-De-Mello (Orgs.). Pesquisa qualitativa em estudos organizacionais: paradigmas, estratégias e métodos (2a ed., pp. 375-40I). São Paulo: Saraiva.

González Rey, F. L. (2005). Pesquisa qualitativa e subjetividade: os processos de construção da informação. São Paulo: Pioneira Thomson Learning.

Ivo, A. B. L. (2007). Cidade - mídia e arte de rua. Caderno CRH, 20(49), IO7-I22.

Jayme, J. G., \& Neves, M. A. (20I0). Cidade e espaço público: política de revitalização urbana em Belo Horizonte. Caderno CRH, 23(60), 605-6I7.

Kissler, L., \& Heidemann, F. G. (2006). Governança pública: novo modelo regulatório para as relações entre Estado, mercado e sociedade? Revista de Administração Pública, 40(3), 479-499.

Lefebvre, H. (2008). O direito à cidade. São Paulo: Centauro.

Linstead, S. A., \& Grafton-Small, R. (I990). Organizational bricolage. In B. A. Turner (Ed.). Organizational symbolism (pp. 29I-309). New York: De Gruyter.

Mac-Allister, M. (200I). Organização-cidade: uma contribuição para ampliar a abordagem do objeto cidade como objeto de estudo no campo dos estudos organizacionais. Tese de doutorado, Universidade Federal da Bahia, Salvador, BA, Brasil.

Mac-Allister, M. (2004). A cidade no campo dos estudos organizacionais. Organizações \& Sociedade, 11, I7I-I8I.

Magnani, J. G. C. (2008). Quando o campo é a cidade: fazendo antropologia na metrópole. In J. G. C. Magnani \& L. L. Torres (Org.). Na metrópole: textos de antropologia urbana (3a ed., pp. I2-53). São Paulo: Edusp, Fapesp.

Maingueneau, D. (I999). Analysing self-constituting discourses. Discourse Studies, 1(2), I75-200. 
Maingueneau, D., Barbosa, M. V., \& Lima, M. E. A. T. (2006). Termos-chave da análise do discurso (2a reimp.). Belo Horizonte: UFMG.

Maricato, E. (20II). As ideias fora do lugar e o lugar fora das ideias: planejamento urbano no Brasil. In O. Arantes, C. Vainer \& E. Maricato. Cidade do pensamento único: desmanchando consensos (6a ed., pp. I2I-I92). Petrópolis: Vozes.

Orlandi, E. P. (2009). Análise de discurso: princípios e procedimentos (8a ed.). Campinas: Pontes.

Paula, A. P. P. (2005). Por uma nova gestão pública: limites e potencialidades da experiência contemporânea. Rio de Janeiro: FGV.

Pesavento, S. J. (2007). Cidades visíveis, cidades sensíveis, cidades imaginárias. Revista Brasileira de História, 27(53), II-23.

Raichelis, R. (2006). Gestão pública e a questão social na grande cidade. Lua Nova, 69, I3-48.

Sánchez, F. (200I). A reinvenção das cidades na virada de século: agentes, estratégias e escalas de ação política. Revista de Sociologia e Política, 16, 3I-49.

Santos, M. (20II). Por uma outra globalização: do pensamento único à consciência universal (20a ed.). Rio de Janeiro: Record.

Saraiva, L. A. S. (2009). Mercantilização da cultura e dinâmica simbólica local: a indústria cultural em Itabira, Minas Gerais. Tese de doutorado, Universidade Federal de Minas Gerais, Belo Horizonte, MG, Brasil.

Saraiva, L. A. S., \& Carrieri, A. P. (20I2). Organização-cidade: proposta de avanço conceitual a partir da análise de um caso. Revista de Administração Pública, 46(2), 547-576.

Secretaria Municipal de Segurança Urbana e Patrimonial (2013). Relatório Movimento Respeito por BH: quem somos. Belo Horizonte: SMSEG.

Spink, M. J., \& Medrado, B. (I999). Produção de sentidos no cotidiano: uma abordagem teórico-metodológica para análise das práticas discursivas. In M. J. Spink (Org.). Práticas discursivas e produção de sentido no cotidiano: aproximações teóricas e metodológicas (pp. 4I-6I). São Paulo: Cortez. Tureta, C., \& Araújo, B. F. V. (20I3). Escolas de samba: trajetória, contradições e contribuições para os estudos organizacionais. Organizações \& Sociedade, 20(64), III-I29.

Wacquant, L. (20IO). Ressituando a gentrificação: a classe popular, a ciência e o Estado na pesquisa urbana recente. Caderno $C R H, 23(58), 5 \mathrm{I}-58$. 